\title{
O DIREITO REAL DE HABITAÇÃO DURADOURA: BREVES NOTAS SOBRE O REGIME LEGAL*
}

\author{
JosÉ Grazina MaChado**
}

\begin{abstract}
SUMÁRIO: 1. Abordagem da noção e características; 2. Modos de constituição;
3. Faculdades do morador; 4. Faculdades do proprietário; 5. Formas de extinção;

6. Conclusões sumárias.
\end{abstract}

Resumo: O presente estudo desenvolve uma breve análise ao regime de um dos direitos reais mais recentes no ordenamento jurídico nacional: o direito real de habitação duradoura.

Trata-se de um instituto jurídico que reclama uma apreciação em termos dogmáticos (teórico e prático). Nesse sentido aborda-se a noção do direito subjetivo, bem como o recorte das principais características, aflorando os modos de constituição do direito, as principais faculdades, os modos de extinção, formulando, a final, as principais conclusões, em termos materiais ou de conteúdo a um tempo.

A outro tempo emprega-se um registo descritivo, embora suscitando, amiúde, algumas questões interpretativas ou aplicativas, problematizando e especulando sobre alguns aspetos controvertidos do regime.

Palavras-Chave: Direito Civil; Direitos Reais; Direito Real de Habitação Duradoura

ABSTRACT: The present study develops a brief analysis of the regime of one of the most recent real rights in the national legal system: the real right to durable housing. It is a legal institute that demands an appreciation in dogmatic terms (theoretical and practical). In this sense, the aim is to approach the notion of subjective law, as well as the main characteristics, highlighting the ways of constituting the law, the main faculties, the extinction modes, formulating, in the end, the main conclusions, in material or of content at a time.

\footnotetext{
* O presente texto tem por base um texto que integra um manual sobre Direito das Coisas, no prelo. Desse texto extraíram-se alguns pontos, suprimindo-se trechos e notas que não cabem na economia e objectivos do texto que ora se apresenta, mas sem tocar, no essencial, no texto primitivo, aduzindo-se alguns pontos de cariz especulativo ou problematizante do regime que se abordará e que ali não se focam, naturalmente.

** Professor Assistente da Faculdade de Direito da Universidade Lusófona (Lisboa).
} 


\section{JOSÉ GRAZINA MACHADO}

At another time, a descriptive record is used, although it often raises some interpretive or applicative questions, problematizing and speculating on some controversial aspects of the regime.

KEYwORDs: Civil Law; Property Law; Real durable housing right 


\section{Abordagem da noção e Características}

O direito real de habitação duradoura é o mais contemporâneo no ordenamento jurídico-real ${ }^{1}$, integra o catálogo dos direitos reais de gozo e justifica uma abordagem dogmática (teórica e prática) acerca do regime legal que não se mostra ainda tratado na doutrina, nem na jurisprudência.

Trata-se de uma situação jurídica compreensiva ${ }^{2}$, que se pode reconduzir à semelhança de outros direitos reais de gozo menores, como jura in re aliena ${ }^{3}$.

A origem do direito real de habitação duradoura, como resulta da exposição de motivos do diploma que o introduziu, reconduz-se à desnecessidade da aquisição da propriedade de um imóvel, para fins habitacionais, mas que justifica a garantia da segurança da solução habitacional das famílias, como ali se afirma.

Aliás, na exposição de motivos consta:

— “(...) Com efeito, em Portugal foi fortemente privilegiado o regime de habitação própria face ao de arrendamento, por diversas razões, das quais se destacam a escassez de oferta e a existência de disfuncionalidades no mercado de arrendamento, a facilidade de obtenção de crédito hipotecário, a disponibilização de apoios do Estado à compra de habitação e aspetos culturais que valorizam a propriedade.

Em resultado, 73\% dos alojamentos familiares clássicos de residência habitual em Portugal são ocupados pelos proprietários, o endividamento dos agregados familiares para aquisição de habitação assume valores muito elevados, o setor do arrendamento é diminuto e pouco acessível em termos de preços e as famílias encontram-se numa situação pouco favorável à mobilidade, o que reduz as suas opções e dificulta a sua adaptação a alterações nas dinâmicas pessoais, familiares e profissionais.

Adicionalmente, coloca-se na atualidade o novo desafio de conciliar as necessidades em termos de estabilidade e de segurança na ocupação do

1 Foi instituído através do Decreto-Lei n. ${ }^{\circ} 1 / 2020$, de 9 de janeiro, precedido de audição ao Conselho Nacional do Consumo.

2 Sobre o conceito vide Menezes Cordeiro, Tratado de Direito Civil Português, I, Parte Geral Tomo

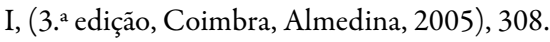

3 Cf. Orlando de Carvalho, Direito das Coisas, (Coimbra, Coimbra Editora, 2012), 245. 
alojamento, cruciais para o desenvolvimento da vida familiar, com as de flexibilidade e mobilidade, que derivam de uma maior mutabilidade dos percursos de vida das pessoas.

Se em muitos casos o regime de habitação própria se tem mostrado pouco adequado pela sua rigidez, pelo peso do investimento que representa e pelas dificuldades de acesso ao mesmo, por outro lado, o regime de arrendamento nem sempre é conducente à estabilidade e segurança desejáveis. (...)”.

O segmento acima transcrito permite descortinar que a génese é suportada por razões socioeconómicas, mas também jurídicas, ainda que ali não afloradas.

$\mathrm{Na}$ dimensão socioeconómica importa ter presente a ausência de intervenção do Estado, enquanto promotor imobiliário, que contribuiu para que, durante décadas, as diversas vertentes do imobiliário, e particularmente o relativo à habitação, conduzisse à sobreprodução de habitação para venda, pautada pela especulação e ainda por processos de revitalização urbana, norteados para a reversão do arrendamento e conducentes ao êxodo populacional do centro para as periferias, nos meios urbanos localizados nas principais áreas metropolitanas nacionais.

Neste cenário regista-se ainda que o poder financeiro e a escala em que intervém permite-lhe dirigir o mercado da habitação na ótica dos preços e das suas flutuações, com particular enfoque no arrendamento, sem que o Estado tivesse assumido qualquer intervenção, quer fosse mais ativa ou meramente regulatória.

Por outro lado, na vertente jurídica, o direito de habitação duradoura visa responder, não olvidando os argumentos aduzidos na exposição de motivos do diploma instituidor, à descaracterização e degradação do regime do arrendamento urbano, maxime do cariz vinculístico, oriundo do direito germânico, de que o imbuía, marcado pela estabilidade e durabilidade.

O Decreto-Lei estabelece, no seu artigo $2^{\circ}$, a noção de direito de habitação duradoura: "O DHD faculta a uma ou mais pessoas singulares o gozo de uma habitação alheia como sua residência permanente por período vitalício, mediante o pagamento ao respetivo proprietário de uma caução pecuniária e de contrapartidas periódicas."

O titular designar-se-á como morador (artigo 3. ${ }^{\circ}$, alínea $c$ ) do DecretoLei n. ${ }^{\circ} 1 / 2020$, de 9 de janeiro - doravante DL n. $\left.{ }^{\circ} 1 / 2020\right)$, recaindo sobre 
um prédio urbano, ou fração autónoma, que se designa por habitação ${ }^{4}$, aí se centrando o objeto do direito real em apreço.

O legislador arriscou a elaboração de uma noção legal, à semelhança da maioria dos direitos reais de gozo plasmados no Código Civil (doravante CCiv.).

A este respeito, a técnica jurídica empregue é perigosa em geral: “(...) pela dificuldade de nelas se incluir toda a realidade abrangida, e pelo facto de serem imprecisas, tecnicamente frágeis e duvidosamente vinculativas em todos os seus detalhes".

Em concreto, a noção acima transcrita não se afigura precisa, visto que é empregue o conceito de gozo, quando, na verdade, melhor se ajustaria o conceito de uso, mercê de ao morador se mostrarem vedadas as faculdades de fruição e disposição.

Por outro lado, a noção é frágil, na medida em que joga com conceitos como "residência permanente", que não é seguramente idêntico a casa de morada de família, visto que a alínea $g$ ) do artigo $3 .^{\circ}$ do diploma define como: "a habitação utilizada, de forma habitual e estável, por uma pessoa ou por um agregado habitacional como centro efetivo da sua vida pessoal e social".

O que aponta ao agregado familiar, mas também à eventual economia comum, como aliás confirma a norma contida na alínea $a$ ) do artigo $3 .^{\circ}$, ao estabelecer como conceito de agregado habitacional: "o conjunto constituído pelas pessoas que têm a sua residência permanente na mesma habitação e mantêm entre si vínculos familiares, de convivência estável e ou de dependência, bem como as situações determinadas por vínculo contratual que implique residência ou habitação comum".

Parece valer aqui o apelo às fontes de relações jus-familiares como o casamento, o parentesco, a adoção, a união de facto, entre outras, para densificar um conceito que embora aparente ser autoexplicativo ou determinado, é portador de subconceitos que tornam mais difícil a leitura e consequentemente a delimitação do espetro do próprio conceito.

4 Cf. alínea $b$ ) do artigo $3 .^{\circ}$ do Decreto-Lei n. ${ }^{\circ} 1 / 2020$, de 9 de janeiro, que estabelece: "o prédio ou fração autónoma de prédio urbano, tal como definidos no $\mathrm{n} .^{\circ} 2$ do artigo $204 .^{\circ}$ e nos artigos $1414 .^{\circ} \mathrm{e}$ $1415 .^{\circ}$ do Código Civil, legalmente apto para ser utilizado para fins habitacionais".

5 Cf. Carlos Pamplona Corte-Real e José Silva Pereira, Direito da Família, Tópicos para uma Reflexão Critica, (Lisboa, AAFDL, 2008), 26. 
A par de tais noções avulta ainda o desvirtuamento do conceito e funções da caução. Ora, a caução é uma garantia especial do cumprimento das obrigações, todavia, o n. ${ }^{\circ} 3$ do artigo $6 .^{\circ}$ do $\mathrm{DL}$ n. ${ }^{\circ} 1 / 2020$ dispõe que: "A caução prestada pelo morador constitui rendimento do proprietário quando e na medida do que dela se pagar nos termos do artigo seguinte", aparentando inculcar a ideia de rendimento, quando na verdade se trata de uma pura garantia que visa prevenir o incumprimento de obrigações assumidas pelo morador e não propriamente de um rendimento; pelo que firmar a caução como fonte de rendimento é deturpar o seu sentido; atente-se no regime contido no $n .^{\circ} 1$ do artigo $623 .^{\circ}$ do CCiv. que aponta no sentido de constituir uma garantia e não um rendimento.

Aflorando o recorte concetual da noção legal extrai-se, reiterando-se, que o objeto se circunscreve única e exclusivamente às coisas corpóreas, imóveis, e mais concretamente destinadas à habitação, postergando-se qualquer fito lucrativo ou capitalístico associado a uma finalidade não habitacional.

Por outro lado, trata-se de um direito cujo âmbito de proteção subjetivo se circunscreve às pessoas singulares, postergando as jurídicas, como admite ainda que seja constituído a favor de uma ou mais pessoas, com o fito de constituir a residência permanente ${ }^{6}$, sendo, portanto, sucessivo.

O titular obriga-se a prestar caução a favor do nu proprietário — garantia cujo capital poderá resultar v.g. no contexto do contrato de mútuo bancário ou de outro contrato de concessão de crédito, assegurado por hipoteca do direito de habitação duradoura a favor de instituição de crédito - além de se vincular à obrigação de pagar um quantitativo pecuniário periódico convencionado no título constitutivo.

Relativamente à caracterização, dir-se-á que se trata de um direito (i) não exclusivo, em linha com os direitos reais de gozo menores, tais como o direito de usufruto, o direito de uso e habitação, entre outros, os quais incidem sobre coisa alheia implicando a existência de outro direito real sobre a coisa.

E corporiza um direito subjetivo (ii) temporário, mercê de não exceder a vida do morador, desvelando a finalidade pessoal (intuitu personae)

6 Cf. alínea $g$ ) do artigo $3 .^{\circ}$ do Decreto-Lei n. ${ }^{\circ}$ 1/2020, de 9 de janeiro, entendendo-se como: "a habitação utilizada, de forma habitual e estável, por uma pessoa ou por um agregado habitacional como centro efetivo da sua vida pessoal e social". 
subjacente à constituição do direito. Acresce ainda que parece resultar do regime legal outra importante limitação: é que não se admite a constituição do direito subordinada a prazo, excluindo-se a aposição de termo ou condição resolutiva ${ }^{7}$. Tal condicionante acaba por constituir um entrave à valorização económica do bem, mas sobretudo à eventual função social que poderia desempenhar.

Outra característica é traduzir-se num direito (iii) limitado quanto ao conteúdo, em razão do morador apenas deter a faculdade de usar a habitação alheia $^{8}$, mas se mostrarem postergadas as faculdades de fruição 9 e disposição ${ }^{10}$, aí se denotando as limitações de cariz negativo.

Essa limitação é ainda confirmada por outro dado relevante. É que o regime do direito real de habitação duradoura não admite a transmissão mortis causa, nem inter vivos, constituindo uma exceção ao princípio da cindibilidade ou da transmissibilidade, sendo, neste último caso, apenas por via da execução da hipoteca tendente à constituição da caução (artigo $12 .^{\circ}$ do DL n. ${ }^{\circ} 1 / 2020$ ) se admite a transmissão do direito, corporizando a exceção que confirma a regra da incindibilidade.

Assinala-se ainda que quer a constituição, quer a extinção do direito real de habitação duradoura estão sujeitas à inscrição no registo predial, nos termos do artigo $22 .^{\circ}$ do DL n. ${ }^{\circ} 1 / 2020$, “(...) consolidando a sua oponibilidade erga omnes perante terceiros (...)"11, devendo constar a duração vitalícia e, sempre que aplicável, a alteração da duração.

7 Cf. Mónica Jardim, Breves notas sobre o Direito Real de Habitação Duradoura, 2020, p. 2 , disponível in https://www.sinoregmg.org.br/post/migalhas-artigo-breves-notas-sobre-o-direito-realde-habita\%C3\%A7\%C3\%A3o-duradoura-por-m\%C3\%B3nica-jardim (consultado em 18.04.2021).

8 Com críticas à definição do direito como facultando o gozo da coisa, quando na verdade viabiliza o uso da mesma, v. Mónica Jardim, Breves notas sobre o Direito Real de Habitação Duradoura, 2020, p. 1, (consultado em 18.04.2021).

9 Tradicionalmente permitem ao titular a obtenção de todas as utilidades ou proveitos/réditos que a coisa produza regularmente.

10 Os quais se desdobram nos poderes materiais, como sejam a transformação ou modificação da coisa, e jurídicos reconduzindo-se ao ato ou negócio de alienação.

11 Cf. Mónica Jardim, Breves notas sobre o Direito Real de Habitação Duradoura, 2020, p. 3 , (consultado em 18.04.2021). 


\section{Modos de CONSTituição}

O direito real de habitação duradoura é constituído, de acordo com o $n .^{\circ} 3$ do artigo $5 .^{\circ}$ do DL $n .^{\circ} 1 / 2020$, por: (i) contrato, o qual deverá ser outorgado por escritura pública ou documento particular, com reconhecimento presencial das assinaturas, configurando a forma ad substantiam, cuja inobservância conduz à nulidade, nos termos gerais do artigo $2200^{\circ}$ do CCiv., visto que não se encontra ali vertida outra sanção. A forma não é paritária, perfilando-se duas modalidades com ritual e força probatória distintas ${ }^{12}$ entre si, por um lado.

Por outro, inexiste no ordenamento jurídico outro direito real, de cariz imobiliário, que seja constituído por documento particular com reconhecimento de assinaturas.

Do conteúdo do vínculo deverá constar a sujeição ao DL n. ${ }^{0} 1 / 2020$, assim como o montante da caução prestada e os valores das contrapartidas a liquidar pelo morador ao nu proprietário, assim como a declaração do morador, tituladora da aceitação do estado de conservação da habitação, determinado de acordo com a ficha de avaliação, que constará como documento complementar do contrato, além dos endereços para as comunicações relativas à execução do contrato (artigo $5 .^{\circ}$, n. ${ }^{\circ} 1$, alíneas a), b) e c)).

Deste modo infere-se que corresponde a um contrato sinalagmático, bivinculante, oneroso, formal, inter vivos, obrigacional e real quoad effectum, causal e típico, como se perscrutará adiante.

Contudo, o DL n. ${ }^{\circ}$ 1/2020 não prevê qualquer outro meio de aquisição do direito real de habitação duradoura, o que permite questionar: poderá ser adquirido por usucapião?

Excluindo o direito de uso e habitação que não pode ser adquirido por usucapião ${ }^{13}$, aparentemente parece que o direito real de habitação duradoura também não pode, em termos distintos.

12 Cf. Mónica Jardim, Breves notas sobre o Direito Real de Habitação Duradoura, 2020, p. 3, (consultado em 18.04.2021).

13 Cf. artigo $1440 .^{\circ}$. 
Por um lado, a lei não estabelece que o direito possa ser adquirido por usucapião, na medida em que o preceito, dotado de imperatividade, vertido no artigo $5 .{ }^{\circ}$ do DL n. ${ }^{\circ} 1 / 2020$ se presta a uma interpretação taxativa.

Por outro, a inobservância da forma legalmente exigida conduz ao sancionamento do negócio com o desvalor da nulidade, visto que o DL n. ${ }^{\circ} 1 / 2020$ não prevê outra sanção.

Acresce ainda e não menos relevante que subsidiariamente se aplicará o regime do direito de uso e habitação (artigo $23 .^{\circ}$ do DL n. ${ }^{\circ} 1 / 2020$ ), no que não seja regulado pelo diploma constitutivo, o que permite concluir finalisticamente, à imagem daquele direito, o direito de habitação duradoura também não se adquire por usucapião.

Em linha com as considerações e sobretudo os atributos do contrato, justifica-se o estudo das faculdades que integram as posições jurídicas subjetivas do morador e do proprietário, seguindo-se de perto a inserção sistemática no texto legal.

\section{FACULDADES DO MORADOR}

A posição jurídica do morador é composta por diversas situações jurídicas compreensivas, resultando diversas situações analíticas cujo estudo se impõe, embora num prisma não exaustivo, procurando destacar as mais relevantes.

Prima facie, o morador está vinculado (i) à obrigação de pagar uma prestação pecuniária, mensal, igual ou desigual, embora sucessiva, por cada mês de duração (artigo $7 .^{\circ}$, n. $^{\circ}$, alínea a)), constituindo uma das principais contrapartidas por conta do uso da habitação, por parte do morador, assim como (ii) prestar caução, pecuniária, liquidada a par da primeira prestação, no ato de outorga do contrato (artigo $5 .^{\circ}$, n. ${ }^{\circ} 7$ ).

A caução cujo montante é convencionado pelas partes deverá corresponder entre $10 \%$ a $20 \%$ do valor mediano das vendas por $\mathrm{m} 2$ de alojamentos familiares, por freguesia, aplicável em função da localização da habitação e da área constante da respetiva caderneta predial, de acordo com a última atualização divulgada pelo Instituto Nacional de Estatística (artigo $6 .^{\circ}$, n. ${ }^{\circ} 1$ ). 
Acresce ainda que o prazo de manutenção da caução é de trinta anos, sendo o valor inicial reduzido em $5 \%$ ao ano, a partir do $11 .^{\circ}$ ano e até ao final do $30 .^{\circ}$ ano de vigência (artigo $6 .^{\circ}, \mathrm{n} .^{\circ} 2$ ).

Não é cristalino se as cifras em causa incidem sobre o valor patrimonial tributário ou sobre o valor comercial do imóvel, sendo que este último é puramente arbitrário e especulativo, suscitando problemas práticos pertinentes, atenta a ambiguidade da redação da norma; como é evidente, é irrelevante de todo condicionar o valor da caução ao valor patrimonial, em regra, mais baixo que o valor comercial, ou então a este último.

O valor da prestação mensal poderá ser objeto de alteração, pressupondo o acordo das partes nesse sentido (artigo $7 .^{\circ}$, n. ${ }^{\circ}$ ), pelo que não se afigura imutável.

O morador goza (iii) do poder de usar a habitação (artigo $9 .^{\circ}, \mathrm{n} .^{\circ} 1$, alínea $a$ )), cabendo-lhe (iv) a obrigação de dare, relativamente às taxas municipais ${ }^{14} \mathrm{e}$ entregar ao nu proprietário os valores relativos ao Imposto Municipal sobre Imóveis (artigo 9. ${ }^{\circ}, \mathrm{n} .^{\circ} 1$, alínea $b$ )).

Depois, sobre o morador impende (v) a obrigação de promover ou permitir a realização das avaliações do estado de conservação da habitação (artigo 9. ${ }^{\circ}$, n. ${ }^{\circ}$, alínea $c$ )), (vi) assim como realizar ou suportar o custo das obras de conservação ordinária da habitação ${ }^{15}$ (artigo $9 .^{\circ}, n^{\circ}{ }^{\circ} 1$, alínea $d)$ ).

Por outro lado, sobre o morador incide (vi) a obrigação de consentir ao nu proprietário a realização das obras relativas às partes comuns do prédio e informá-lo, logo que tenha conhecimento, da existência de anomalias na habitação cuja reparação impenda sobre o proprietário (artigo $9 .^{\circ}, \mathrm{n} .^{\circ}$ 1 , alínea $e)$ ). As últimas obrigações que se vêm de aflorar reconduzem-se, quanto ao conteúdo, a prestações de facere.

Findo o contrato, o morador (vii) obriga-se a entregar a habitação ao proprietário com nível de conservação médio, livre de pessoas (artigo $19 .^{\circ}$, n. $^{\circ} 1$ ), desfrutando (viii) do direito a receber o saldo da caução, além

14 V.g. água, saneamento, resíduos sólidos, entre outras.

15 Cf. alínea d) do artigo $3 .^{\circ}$ do Decreto-Lei n. ${ }^{\circ} 1 / 2020$, de 9 de janeiro, entendendo-se como: "as obras de reparação de deteriorações na habitação resultantes do envelhecimento dos materiais e ou do seu desgaste pelo uso normal, nestas se incluindo as benfeitorias necessárias a que se destinem a evitar a deterioração dos mesmos e a garantir um estado de conservação, no mínimo, médio". 
de (ix) gozar de privilégio imobiliário especial sobre a habitação, o qual é graduado depois dos créditos referidos na alínea $b$ ) do n. 2 do artigo $333 .^{\circ}$ do CTrabalho e antes créditos referidos no artigo $748 .^{\circ}$ do CCiv. e dos créditos relativos a contribuições para a segurança social, caso cesse o contrato e o nu proprietário não devolva o saldo da caução, gozando, portanto, de um direito real de garantia.

O apelo ao conceito indeterminado ou impreciso, nível de conservação médio, poderá potenciar a ocorrência de litígios.

Estas situações jurídicas compõem, no essencial, a posição jurídica do morador e prestam-se a crítica.

Desde logo e sumariamente pela ausência do direito de preferência, em caso de venda ou dação em cumprimento, da habitação, pelo nu proprietário.

Aliás, o único direito de preferência que assiste ao morador, poderá ser exercido na hipótese do decurso da execução de hipoteca constituída sobre o direito de propriedade, configurando uma limitação drástica à tutela da posição jurídica subjetiva do morador.

Por outro lado, o apelo ao conceito indeterminado ou impreciso, nível de conservação médio, poderá contribuir para o surgimento de litígios, fruto da amplitude interpretativa que proporciona ao intérprete-aplicador; uma solução de lege ferenda seria expurgar tal conceito e considerar-se que o imóvel deveria ser restituído em condições idênticas àquelas que reunia, aquando da entrega pelo proprietário no início do contrato.

\section{Faculdades do proprietário}

Por sua vez, a posição jurídica subjetiva do proprietário é composta por diversas situações jurídicas que importa perscrutar.

Previamente à outorga do contrato, ao proprietário compete (i) a obrigação de promover a avaliação prévia do estado de conservação da habitação, a qual deverá ser realizada por arquiteto, engenheiro ou engenheiro técnico inscrito na respetiva ordem profissional, o qual não poderá estar em 
incompatibilidade ou impedimento (artigo $4 .^{\circ}, n .^{\circ} 1$ ), correspondendo a uma obrigação de facere.

Note-se que a referida avaliação deve assegurar o registo fidedigno do estado da habitação há menos de 12 meses (artigo 4. ${ }^{\circ},{ }^{\circ}{ }^{\circ}$ 2).

Já no âmbito da execução do contrato incumbe ao proprietário (ii) a obrigação de entregar a habitação ao morador, num estado de conservação médio (artigo 8..$^{\circ}$ alínea a)), como também (iii) abster-se de praticar qualquer ato que perturbe ou diminua o gozo por parte do morador, assim como (iv) suportar o pagamento dos custos de obras e demais encargos relativos às partes comuns do prédio, além das quotas do condomínio, caso a habitação se integre em prédio constituído sob propriedade horizontal.

Depois recai sobre o proprietário (v) a obrigação de assegurar a outorga e pagamento dos seguros legalmente exigidos (artigo $8 .^{\circ}$, alínea $b$ )), além de (vi) realizar e suportar as obras de conservação extraordinárias na habitação ${ }^{16}$, a menos que as anomalias existentes decorram da prática de atos ilícitos ou do incumprimento das obrigações do morador (artigo $8 .^{\circ}$, alínea $d$ )), e ainda, (vii) gerir o montante recebido adveniente da caução (artigo $8 .^{\circ}$, alínea $e$ )).

A seguir, o proprietário (viii) não pode constituir quaisquer direitos reais ou garantias sobre a habitação, com exceção da hipoteca (artigo 11. ${ }^{\circ},{ }^{\circ} .^{\circ} 1$ ), embora possa dispor inter vivos ou mortis causa do direito de propriedade sobre a habitação, assinalando-se conclusivamente, como uma limitação de interesse privado, em razão da ausência de poderes de oneração, mas já não de disposição visto que se admite a transmissibilidade.

Em caso de extinção do contrato por execução da hipoteca, o proprietário goza do (ix) direito de preferência, no âmbito da ação executiva (artigo 21. ${ }^{\circ}$, n. ${ }^{\circ}$ ) que seja movida contra o morador.

Como se pode constatar, o legislador procedeu à densificação, até em certa medida exaustiva, das situações jurídico-reais do morador e do proprietário corporizado num regime particularmente exigente.

16 Cf. alínea e) do artigo $3 .^{\circ}$ do Decreto-Lei n. ${ }^{\circ} 1 / 2020$, de 9 de janeiro, entendendo-se como "as obras necessárias à reposição das condições de segurança, salubridade e conforto da habitação por anomalias que não sejam decorrentes do envelhecimento dos materiais e ou do seu desgaste pelo uso normal, incluindo as benfeitorias necessárias que se destinem a evitar a perda ou destruição da habitação". 


\section{FORMAS DE EXTINÇÃo}

Relativamente à cessação do direito de habitação duradoura, o DL n. ${ }^{\circ}$ 1/2020 prevê como causas extintivas: (i) a morte do morador ou se constituído a favor de mais do que uma pessoa, com a morte do último ${ }^{17}$, (ii) a renúncia ${ }^{18}$ - a qual apresenta natureza abdicativa, (iii) o incumprimento definitivo do contrato $^{19}$, o qual poderá acontecer na sequência do não pagamento, total ou parcial, por qualquer das partes dos montantes devidos à contraparte, após o termo do prazo da interpelação a que alude os n. ${ }^{\text {os }} 2$ e 3 do artigo $14 .^{\circ}$, ou por reincidência de constituição de mora por parte do morador; com um ou outro fundamento, a resolução é decretada nos termos da lei de processo ${ }^{20}$.

A par das três causas extintivas, se bem vemos o regime, deverão aplicar-se outros fundamentos de cessação, porém, com recurso ao regime do direito de uso e habitação, os quais promanam do regime do direito de usufruto, resumindo-se assim: (iv) à reunião da habitação duradoura e da propriedade na mesma pessoa, na qual o morador poderá utilizar o montante da caução, cuja devolução tenha direito para compensar, total ou parcialmente, a obrigação de pagamento do preço (artigo $11^{\circ}$, n. $^{\circ} 2$ ), (v) o não exercício durante 20 anos, qualquer que seja o motivo e (vi) a perda total da habitação, nos termos do artigo $1476 .^{\circ}$, alíneas b), c) e d), ex vi artigo $1485 .^{\circ}$, ex vi artigo $23 .^{\circ}$ do DL n. $.^{\circ} 1 / 2020$.

\section{CoNClusốes SUMÁRias}

A exposição de motivos e o texto legal em apreço revelam que o diploma em causa consubstancia um direito real positivado na lógica da tutela do direito fundamental à habitação, previsto no $n .^{\circ} 1$ do artigo $65^{\circ}$ da Constituição da República.

Contudo, apesar da bondade da medida legislativa adotada, antevê-se que o direito real em causa terá diminuta expressão na ordem social.

\footnotetext{
17 Cf. artigo $16^{\circ}$.

18 Cf. artigo $17 .{ }^{\circ}$.

19 Cf. artigo $18 .^{\circ}$.

20 Cf. artigo $18 .^{\circ}$, n. ${ }^{\circ}$.
} 
Desde logo porque é pouco crível que as instituições de crédito tenham interesse em mutuar quantias, garantidas por um direito cujo valor económico é duvidoso, por um lado.

Por outro poderá questionar-se, legitimamente, que, quem pretenda constituir um direito real de habitação douradora não ambicione, ao invés, a constituição do direito de propriedade, atentas as vantagens económicas e jurídicas daí resultantes, contrariamente àquele, perfilando-se um direito inútil no prisma socioeconómico.

Aliás, melhor seria o putativo morador adquirir uma habitação contraindo um mútuo garantido por hipoteca tendente à aquisição da propriedade, possivelmente liquidando mensalmente valores pecuniários menores, ante os que pagaria no quadro do mútuo para prestar a caução, e sempre adquiriria o direito de propriedade sobre o bem, cujo conteúdo económico é inegavelmente mais fidedigno.

Aliás, a exigência da constituição da caução, assim como os pagamentos mensais por parte do morador constituem uma forma de financiamento brutal do nu proprietário, fora do sistema financeiro e sem qualquer regulação, denotando a assimetria das posições jurídicas do nu proprietário e do morador.

E note-se que a desigualdade no plano contratual em apreço não é sequer mitigada com quaisquer outras medidas previstas no diploma.

Todavia, o problema de fundo que se revela neste direito real de habitação duradoura reside nas alterações legislativas que foram postergando a qualificação do direito do arrendatário como direito real, sendo lido como um direito de matriz obrigacional, abalando o cunho vinculístico inerente ao contrato de arrendamento para fins habitacionais.

Hodiernamente, na dogmática civilista, a discussão em torno da natureza jurídica do direito do locatário ainda se mantém ${ }^{21}$, embora

21 No sentido de que se trata de um direito real, vide Menezes Cordeiro, Tratado de Direito Civil português I. Parte geral, tomo II, (Almedina, Coimbra, 2002), 687. Considerando que "no início, o arrendamento é direito de crédito, no final será direito real", Oliveira Ascensão, Locação de bens dados em garantia, 2002, 367. Sem uma posição fixa entendendo que o direito do locatário se afigura híbrido por existirem aspetos de regime que o aproximam da natureza real, em simultâneo da matriz obrigacional, Carvalho Fernandes, Liçôes de Direitos Reais, (Quid Iuris, Lisboa, 2001), 173. Considerando que se trata de um direito de cariz obrigacional, defendido em alguns aspetos pela denominada tutela forte dos direitos reais, A. Santos Justo, Direitos Reais, (Coimbra Editora, Coimbra, 2007), 429. 
na jurisprudência seja pacífico que se trata de um direito de índole obrigacional ${ }^{22}$.

Por conseguinte, o direito real em apreço pelos traços gerais do regime abordado não acompanha os propósitos vertidos na exposição de motivos, como também parece estar votado ao insucesso e pegando na lapidar frase constante, a final, da exposição de motivos: “(...) atenta a adoção do instituto do direito real de habitação para situações em que, não se justificando a aquisição da propriedade, se revelava necessário garantir a segurança da solução habitacional, como nos casos do direito de habitação atribuído pelo DecretoLei n. ${ }^{\circ}$ 502/99, de 19 de dezembro, na sua redação atual, e pela Lei n. ${ }^{\circ}$ 7/2001, de 11 de maio, na sua redação atual, foi adotada uma solução idêntica para o direito criado pelo presente decreto-lei”; afigura-se uma contradição analítica nos termos: como se poderá garantir a segurança habitacional, se o regime legal adotado desequilibra a relação jurídico-real em favor do proprietário?

É que o segmento em apreço descortina o paradoxo entre a desnecessidade de aquisição de propriedade e a garantia da solução habitacional, à qual se conclui que ainda não passará seguramente pelo instituto que se vem de aflorar.

Por outro lado, crê-se que o direito real de habitação duradoura, à luz das características próprias acima perscrutadas, conferem-lhe autonomia, sendo um direito real de gozo menor, que se aproxima em vários aspetos de regime do direito de habitação ainda que obtemperado à prestação de caução e das contrapartidas pecuniárias que atribuem a este direito subjetivo, além de execução da caução, os principais traços de assimetria face àquele direito.

22 Entre outros, assinala-se o douto Acórdão proferido pelo Supremo Tribunal de Justiça no processo n. ${ }^{\circ}$ 03B3610, datado de 27.11.2003 e relatado por Quirino Soares. 
